\title{
Unusual communication of profunda femoris vein with the popliteal vein in the middle of the popliteal fossa
}

\author{
Satheesha Badagabettu Nayak, Srinivasa Rao Sirasanagandla ${ }^{*}$, Sudarshan Surendran, \\ Vasanthakumar, Venu Madhav Nelluri \\ Melaka Manipal Medical College (Manipal Campus), Manipal University, Manipal, India; \\ *Corresponding Author: seenaih.anat@gmail.com
}

Received 18 May 2013; revised 12 July 2013; accepted 20 July 2013

Copyright (C) 2013 Satheesha Badagabettu Nayak et al. This is an open access article distributed under the Creative Commons Attribution License, which permits unrestricted use, distribution, and reproduction in any medium, provided the original work is properly cited.

\begin{abstract}
Profunda femoris vein (PFV) rarely forms a direct communication with the lower end of the femoral vein (FV) or popliteal vein (PV). During regular dissections for medical undergraduates, we came across a rare anatomical variation of PFV in the right lower limb of an 80-year-old female cadaver. PFV commenced from the PV just above its formation by the union of anterior and posterior tibial veins. It traversed the popliteal fossa on the lateral side of the popliteal artery and entered into the adductor canal after piercing the adductor magnus muscle. Finally, it emptied into the FV in the lower part of the femoral triangle. Furthermore, the PV had a small caliber than that of PFV. Deep veins of leg are the common site for formation of thrombosis. In terms of diagnosis and operative procedures, the location of thrombosis in the deep veins of lower limb is clinically of great importance. Thus detailed knowledge of the anatomical variation reported here is useful during diagnosis and treatment of deep vein thrombosis.
\end{abstract}

Keywords: Profunda Femoris Vein; Communication; Popliteal Vein; Femoral Vein; Thrombosis

\section{INTRODUCTION}

Classically, the PV is formed by the union of the posterior and anterior tibial veins, at the lower portion of the popliteus muscle. It traverses the popliteal fossa lying superficial and lateral to the popliteal artery. After passing through the 5th osseoaponeurotic opening of the adductor magnus muscle, it continues as the FV. The FV traverses the femoral triangle and ends by continuing as external iliac vein. PFV is usually formed by the small veins accompanying the branches of the profunda femoris artery. Sometimes, PFV receives the lateral and medial circumflex femoral veins and finally drains into femoral vein distal to the saphenofemoral junction [1]. PFV may communicate with the lower part of the FV [2] or with the PV [3-7]. However, the formation of PFV by the tibial veins has been reported once in a while in the past [8]. Herein, we report a case of communication of PFV with the lower part PV immediately above its formation and discuss its clinical importance.

\section{CASE REPORT}

During a regular dissection for first year medical students, we came across a rare variation of PFV, in an 80 -year-old female cadaver of South Indian origin. It was a unilateral variation and was observed in the right lower limb of female body that was donated to the Manipal University, for the purpose of the medical education and anatomical research. PV was formed in the middle of the popliteal fossa by the union of anterior and posterior tibial veins. It was about $8 \mathrm{~cm}$ in length, and presented two distinct segments; the small distal thick segment (1 $\mathrm{cm})$ and proximal thinner segment $(7 \mathrm{~cm})$. PFV commenced from the lower part of the PV just above its formation by tibial veins. Then, it traversed the popliteal fossa on the side of popliteal artery and entered the adductor canal by piercing the adductor magnus muscle. Finally, it emptied into the FV in the lower part of the femoral triangle. In the posterior compartment of the thigh, it was situated superficial to the adductor magnus and was covered by the hamstring muscles, sciatic nerve and its branches. It was about $20 \mathrm{~cm}$ in length and presented same caliber throughout its course (Figures 1 and 2). 


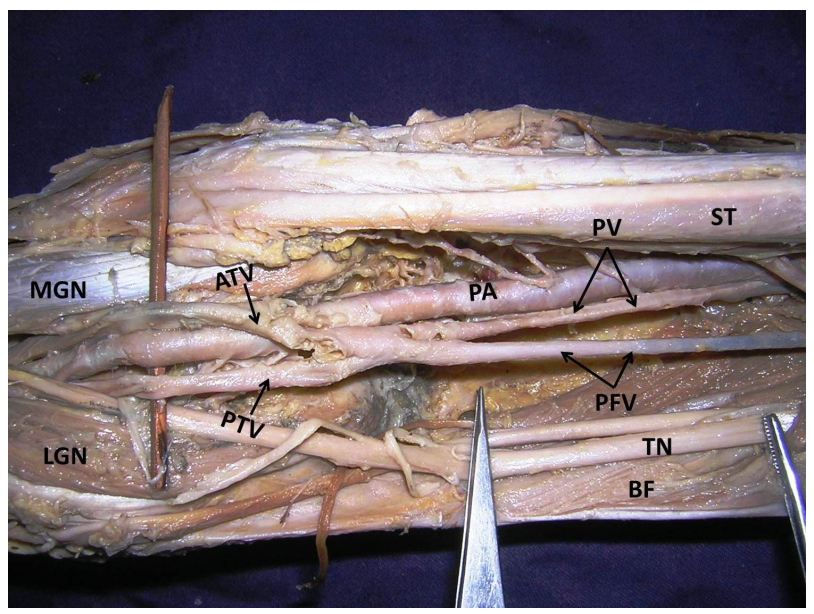

Figure 1. Dissection of the right popliteal fossa showing unusual communication of profunda femoris vein (PFV) with the popliteal vein (PV) in the middle of the popliteal fossa. (PA: popliteal artery, ATV: anterior tibial vein, PTV: posterior tibial vein, ST: semitendinosus, BF: biceps femoris, TN: tibial nerve, LGN: lateral head of gastrocnemius, MGN: medial head of gastrocnemius).

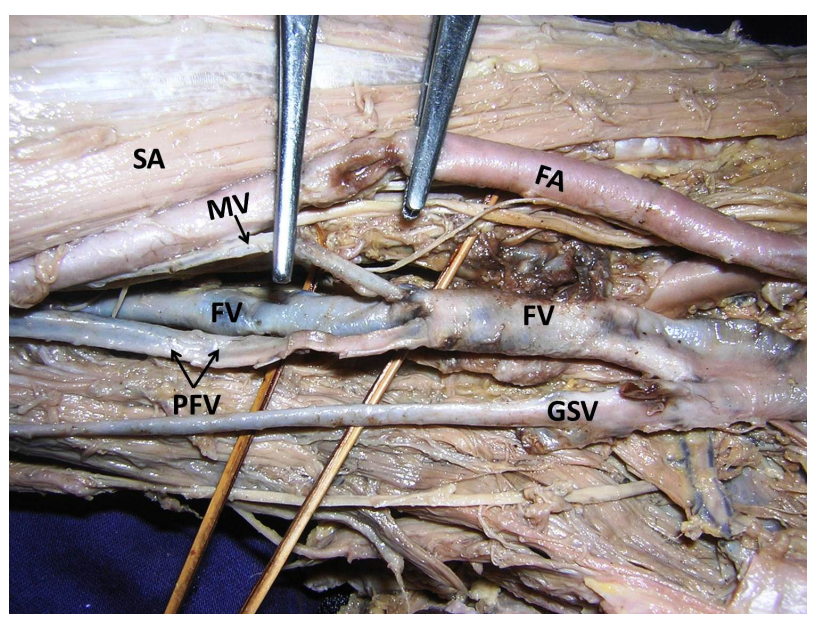

Figure 2. Dissection of front of the thigh showing the termination of profunda femoris vein (PFV) into the femoral vein (FV). Note the course of the PFV in the adductor canal, deep to the sartorius muscle (SA) along with the FV. (MV: muscular vein, FA: femoral artery, GSV: great saphenous vein).

\section{DISCUSSION}

The anatomy of the lower limb venous system is highly variable $[9,10]$. Most of the venous variations have been studied through cadaveric dissections, venography or ultrasonography. FV and PV frequently show variations in their formation, course, and number [11]. However, the variations of the PFV are not very common. The PFV may communicate with the lower end of the FV [2] or it may communicate with the PV [3-7]. Edwards and Robuck have reported a case in which PFV communicated with the lower part of the FV [2]. Henry Gray has reported a case in which PFV, communicated distally with the PV through its tributaries, and proximally with the inferior gluteal veins [3]. Mavor and Galloway have found the incidence of communication of PFV with PV in $38 \%$ of cases [4]. Jiji et al. [5] and Kacar and Barut [6] have reported the cases of direct communication of PFV with the PV. Contrary to previous reports, Sujatha et al. have reported a rare case in which PFV was formed at the upper end of the popliteal fossa by the tibial veins, replacing the most of the PV. In their case, PFV terminated into the FV at the level of lesser trochanter by passing above the origin of the adductor magnus [8]. In the present case, the PFV commenced from the PV immediately above its formation by the tibial veins, in the middle of the popliteal fossa. PFV pierced the adductor magnus and entered the adductor canal. After traversing the adductor canal as its content, it emptied into the FV at the lower part of femoral triangle. Though the communication of PFV with PV has been reported earlier, the PFV observed here is unique in its site of formation and had a larger caliber than the PV. Occurrence of direct communication of PFV with the PV can be explained by understanding the developmental stages of the embryonic axial vein [7]. The PFV represents the cephalic remnant of the embryonic axial vein which is the main outflow source of the lower limb [12]. PV represents the caudal remnant of the axial vein. Subsequently, the intervening portion between the two segments disappears and finally the PV anastomoses with the superficial femoral vein pertaining to the preaxial vessels. Persistence of the intervening portion leads to the formation of communication between the PV and PFV [7]. The unequal blood flow through the intervening portion and caudal remnant of the axial vein may explain why the caliber of the PFV observed was significantly more than that of the PV.

PFV is one of the potential sites for thrombus formation in the lower limb. Thrombosis of the PFV may lead to pulmonary embolism. As phlebography technique cannot visualize the PFV, duplex sonography is frequently used to diagnose the suspected thrombosis of the leg veins [13]. Many patients with deep vein thrombosis remain asymptomatic, as anatomic variations of deep veins may form the collateral circulation. It has been suggested that any obstruction or presence of thrombosis in the FV may cause enlargement of non-functional highresistance anastomosis between the PV and PFV and this anastomosis can function as a collateral circulation [7]. The awareness of variations of PFV is clinically important during the diagnosis and planning the interventional procedures particularly ligating the veins to prevent the spread of deep vein thrombosis.

\section{REFERENCES}

[1] Standring, S. (2008) Gray's anatomy: The anatomical 
basis of clinical practice. 40th Edition, Churchill \& Livingstone, Edinburgh.

[2] Edwars, E.A. and Robuck, J.D. (1947) Applied anatomy of the femoral vein and its tributaries. Surgery Gynecology \& Obstetrics, 85, 547-557.

[3] Gabella, G. (1996) Cardiovascular system. In: Williams, P.L., Bannister, L.H., Berry, M.M., et al., Eds., Gray's Anatomy: The Anatomical Basis of Medicine and Surgery. 38th Edition, Churchill Livingstone, Edinburgh, 1598.

[4] Mavor, G.E. and Galloway, J.M. (1967) Collaterals of the deep venous circulation of the lower limb. Surgery Gynecology \& Obstetrics, 125, 561-571.

[5] Jiji, P.J., D’Costa, S., Prabhu, L.V., et al. (2007) A rare variation of the profunda femoris vein in the popliteal fossa. Singapore Medical Journal, 48, 948-949.

[6] Kacar, D. and Barut C. (2012) A rare variation of profunda femoris vein directly communicating with popliteal vein. Medical Journal of Islamic World Academy of Sciences, 20, 70-72.

[7] Natsis, K., Totlis, T., Paraskevas, G., et al. (2008) Axial transformation of the profunda femoris vein: Formation, relations and course in a cadaveric specimen. Folia Morphologica, 67, 304-306.

[8] Sujatha, K., Arvind, C.H. and Naveen, T. (1997) A rare variation of deep femoral vein. Indian Journal of Medical
Sciences, 51, 82-84.

[9] Cross, L., Hall, J., Howdieshell, T.R., et al. (2000) Clinical anatomy of the popliteal blood vessels. Clinical Anatomy, 13, 347-353.

http://dx.doi.org/10.1002/1098-2353(2000)13:5<347::AI D-CA4>3.0.CO;2-9

[10] Uhl, J.F., Gillot, C. and Chahim, M. (2010) Anatomical variations of the femoral vein. Journal of Vascular Surgery, 52, 714-719. http://dx.doi.org/10.1016/j.jvs.2010.04.014

[11] Park, E.A., Chung, J.W., Lee, W., et al. (2011) Threedimensional evaluation of the anatomic variations of the femoral vein and popliteal vein in relation to the accompanying artery by using CT venography. Korean Journal of Radiology, 12, 327-340. http://dx.doi.org/10.3348/kjr.2011.12.3.327

[12] Raju, S. and Hardy, J.D. (1997) Technical options in venous valve reconstruction. The American Journal of Surgery, 173, 301-307. http://dx.doi.org/10.1016/S0002-9610(96)00394-7

[13] Habscheid, W. (1999) Isolated thrombosis of the vena profunda femoris as the source of embolisms. A diagnosis easy to supply using duplex sonography. Deutsche Medizinische Wochenschrift, 124, 793-796. http://dx.doi.org/10.1055/s 